\title{
E QUANDO A CRIANÇA NÃO CORRESPONDE ÀS EXPECTATIVAS DA ESCOLA? REFLEXÕES SOBRE A RELAÇÃO COM A FAMÍLIA NA BUSCA POR UM DIAGNÓSTICO
}

\author{
¿Y CUANDO EL NIÑO NO ESTÁ A LA ALTURA DE LAS EXPECTATIVAS DE LA \\ ESCUELA? REFLEXIONES SOBRE LA RELACIÓN CON LA FAMILIA EN LA \\ BÚSQUEDA DE UN DIAGNÓSTICO
}

\begin{abstract}
AND WHAT ABOUT WHEN THE CHILD DOES NOT MATCH THE SCHOOL'S EXPECTATIONS? REFLECTIONS ON RELATIONSHIP WITH THE FAMILY IN THE SEARCH FOR A DIAGNOSIS
\end{abstract}

\author{
Luciana Aparecida de ARAUJO ${ }^{1}$ \\ Cleriston Izidro dos ANJOS $^{2}$ \\ Fábio Hoffmann PEREIRA ${ }^{3}$
}

RESUMO: O objetivo deste artigo é compreender o modo pelo qual a escola tem respondido a crianças diagnosticadas com Transtorno de Déficit de Atenção e Hiperatividade (TDAH) do ponto de vista do trabalho pedagógico e da relação com a família. Mediante pesquisa bibliográfica e de um estudo de caso, traz a história de uma criança de 8 anos, com hipótese diagnóstica de TDAH. Os dados foram coletados por meio de narrativa da mãe e registros em diário de campo. Os resultados revelam que o ofício de aluno exigido pela escola vai além dos aspectos cognitivos e da aprendizagem dos conteúdos, envolvendo uma expectativa dos adultos a respeito de um "modo de ser na escola". Conclui-se que a escola deve acolher a diversidade e a diferença, para não incorrer em estratégias de defesa e desresponsabilização do trabalho pedagógico.

PALAVRAS-CHAVE: Educação. Dificuldades escolares. Diagnóstico. TDAH. Relação família-escola.

RESUMEN: El objetivo de este artículo es comprender la forma en que la escuela ha respondido a los niños diagnosticados con trastorno por déficit de atención e hiperactividad (TDAH) desde el punto de vista del trabajo pedagógico y de la relación con la familia. A través de la investigación bibliográfica y un estudio de caso, trae la historia de un niño de 8 años, con una hipótesis diagnóstica de TDAH. Los datos se recopilaron a través de la narrativa y los registros de la madre en un diario de campo. Los resultados revelan que el trabajo del estudiante exigido por la escuela va más allá de los aspectos cognitivos y el

\footnotetext{
${ }^{1}$ Universidade Estadual Paulista (UNESP), Marília - SP - Brasil. Docente no Programa de Pós-Graduação em Educação (PPGE) e no Departamento de Didática, Faculdade de Filosofia e Ciências (FFC). Doutorado em Educação (UNESP). ORCID: https://orcid.org/0000-0003-1147-5039. E-mail: luciana.penitente@unesp.br

${ }^{2}$ Universidade Federal de Alagoas (UFAL), Maceió - AL - Brasil. Professor Adjunto no Setor de Estudos de Educação Infantil. Doutorado em Educação (UFAL). ORCID: https://orcid.org/0000-0003-1040-4909. E-mail: cianjos@yahoo.com.br

${ }^{3}$ Universidade Federal de Alagoas (UFAL), Arapiraca - AL - Brasil. Professor no Curso de Pedagogia. Doutorado em Educação (USP). ORCID https://orcid.org/0000-0002-2933-2610. E-mail: hoffmann@arapiraca.ufal.br
} 
aprendizaje del contenido, lo que implica la expectativa de un adulto sobre una "forma de ser en la escuela". Se concluye que la escuela debe abrazar la diversidad y la diferencia, para no incurrir en estrategias para la defensa y la responsabilidad del trabajo pedagógico.

PALABRAS CLAVE: Educación. Dificultades escolares. Diagnóstico. TDAH. Relación familia-escuela.

ABSTRACT: The objective of this article is to understand the way in which the school has responded to children diagnosed with Attention Deficit Hyperactivity Disorder (ADHD), from the point of view of pedagogical work and the relationship with the family. Through a bibliographic research and a study of a case, it brings the story of an 8-year-old child with a diagnostic hypothesis of ADHD. Data was collected through the mother's narrative and recorded in a field diary. The results reveal that the student's task demanded by the school goes beyond cognitive aspects and content learning, involving an adult's expectation about a "way of being school". It is concluded that the school must embrace diversity and difference, so as not to incur in strategies for the defense and no responsibility of pedagogical work.

KEYWORDS: Education. School difficulties. Diagnosis. ADHD. Family-school relationship.

\section{Introdução}

O encaminhamento de crianças para as redes de saúde em busca de avaliação médica tem sido cada vez mais frequente. Neurologistas, psiquiatras e psicólogos recebem crianças encaminhadas por docentes e outros/as profissionais da escola para avaliação médica, resultando no aumento do número de diagnósticos de crianças e, consequentemente na indicação de uso de medicamentos (MOYSÉS; COLLARES, 1994).

Isso se deve a uma série de dificuldades de adaptação das crianças à rotina escolar, que aqui chamaremos de "dificuldades escolares", aquelas que não se referem, necessariamente, a dificuldades de aprendizagem, mas na compreensão de como o "ofício de aluno" deve ser configurado e performado na instituição escolar (CHARLOT, 2000; PERRENOUD, 1995; PEREIRA, 2015), como por exemplo, em organizar o próprio material, em concentrar-se na realização de tarefas, em fazer-se visível aos olhos da professora ou do professor, em colocarse em uma discussão coletiva, entre outros aspectos. Neste contexto, muitas vezes, a lógica da instituição escolar parece reiterar a ideia de que as dificuldades escolares seriam responsabilidade das crianças e/ou de suas famílias. Essa responsabilidade é geralmente associada à presença de algum tipo de transtorno ou ao contexto social, econômico e cultural no qual as crianças estariam inseridas. Dessa forma, entendemos por dificuldades escolares não apenas as dificuldades relacionadas à aprendizagem, mas também a questões relacionadas ao comportamento esperado pelos adultos com relação às crianças. Entre as dificuldades 
escolares que poderão resultar em possíveis diagnósticos, destacamos neste artigo os sintomas do chamado Transtorno de Déficit de Atenção e Hiperatividade (TDAH).

Partimos do pressuposto de que práticas discursivas negativas ao desenvolvimento escolar da criança podem acarretar um processo de prejuízo à imagem de si mesma e comprometer a sua constituição como pessoa e aprendiz. Ademais, as dificuldades da escola em lidar com dificuldades escolares e a consequente busca por um diagnóstico poderão servir como justificativas para a não aprendizagem como uma responsabilidade das crianças e de suas famílias, isentando a escola de qualquer responsabilidade neste processo (MOYSÉS, 2001).

É com base nesse contexto que o objetivo deste artigo se justifica em compreender o modo pelo qual a instituição educacional tem respondido a casos de crianças com hipótese diagnóstica de Transtorno de Déficit de Atenção e Hiperatividade (TDAH), do ponto de vista do trabalho pedagógico e da relação com a família.

O TDAH está apresentado no Manual Diagnóstico e Estatístico de Transtornos Mentais DSM-V como categoria de distúrbio psiquiátrico, trazendo como principal característica a desatenção, a hiperatividade/impulsividade ou as duas características combinadas. No entanto, o que dificulta o diagnóstico do TDAH são as comorbidades associadas a eles, daí os motivos pelos quais os médicos, psiquiatras e psicólogos dependem do relato da família e dos docentes, pois nenhum exame laboratorial é capaz de diagnosticá-lo (SANCHES et al., 2019).

Cabe destacar que existem diferentes visões e posicionamentos sobre TDAH. A corrente organicista, por exemplo, defende o TDAH como um transtorno de caráter neurobiológico que provoca sinais de hiperatividade, impulsividade e desatenção devido a uma falha genética, que é insuficiente no que diz respeito aos neurotransmissores do cérebro. Para eles, essa falha pode ser corrigida com medicamentos estimulantes como o metilfenidato (SIGNOR, 2016), cuja marca mais popular no Brasil é conhecida como Ritalina ${ }^{\circledR}$.

Ao contrário dos organicistas, a vertente sócio-histórica, assumida por Signor (2016), defende que o TDAH não se trata de uma questão decorrente de uma condição neurobiológica, mas de uma série de situações que podem interferir no desenvolvimento da criança e nas dificuldades que se manifestam na escola e que são construídas socialmente (SIGNOR, 2016). 


\section{Percurso metodológico}

Em uma primeira fase, a pesquisa que fez parte deste estudo caracterizou-se como bibliográfica no que diz respeito à natureza de suas fontes, realizada a partir de registro decorrente de pesquisas anteriores, em documentos impressos como livros, artigos, teses e dissertações. No segundo momento da investigação foi realizado um estudo de caso com crianças do $3^{\circ}$ ano do Ensino Fundamental de uma escola privada do Oeste Paulista. Os critérios utilizados para a seleção das crianças foram: estudantes com hipótese diagnóstica ou com diagnóstico médico concluso de TDAH e que houvesse disponibilidade e interesse da família em participar da pesquisa. $\mathrm{O}$ contato com as famílias foi realizado a partir de informações da escola de casos considerados como de crianças que apresentavam algum tipo de dificuldade escolar e que, por esse motivo, a instituição tivesse acionado a família como tentativa para a superação daquilo que a escola considerava como um problema a ser resolvido. Para este artigo, optamos por trazer para a discussão uma síntese dos relatos da mãe de Ítalo (nome fictício), um menino de oito anos de idade com hipótese diagnóstica de TDAH, matriculado em uma das turmas da pesquisa.

Optamos pelo estudo de caso por sua contribuição para análise da prática educacional, focalizando uma instância particular e seu movimento natural, uma vez que pode trazer informações importantes de natureza prática e política (ANDRÉ, 2005). Ademais, nos inspiramos na pesquisa narrativa, cuja investigação se desenvolve a partir dos relatos das pessoas sobre suas vidas, sendo recontada pelo pesquisador a partir de sua percepção, com base em uma cronologia narrativa e colaborativa (CLANDININ; CONNELY, 2000 apud CRESWELL, 2010).

Tanto a coleta como a divulgação dos dados foram asseguradas por princípios éticos, visando garantir o respeito aos sujeitos, o anonimato e evitando-lhes prejuízos. Os dados foram registrados mediante gravação em áudio, que serviu como importante instrumento ao permitir liberdade na condução das questões, favorecendo a interlocução e avanço nas problematizações e registro em diário de campo.

A partir da síntese do relato da mãe de Ítalo sobre o percurso vivido na busca de respostas para o caso de seu filho, optamos por trazer para este artigo as informações relacionadas ao modo por meio do qual a instituição educacional procurou dialogar com a família na busca por um diagnóstico, tendo em vista o fato de que a instituição parte do princípio de que a dificuldade está na criança e não em outros possíveis fatores, tais como aqueles relacionados ao trabalho pedagógico ou à estrutura e funcionamento escolar. 
Os dados coletados mediante relatos da mãe foram analisados a partir de dois eixos, a saber: 1) Diagnóstico: que se refere ao processo de busca da família por uma avaliação com especialistas da área da saúde a partir de solicitação insistente da escola, os conflitos e angústias da família em relação ao diagnóstico e a medicalização da criança e; 2) Relação família-escola: que traz reflexões a respeito da responsabilidade da instituição educacional no que se refere ao trabalho pedagógico e à sua estrutura e funcionamento como dimensões que podem interferir nas dificuldades das crianças, pois a busca de um diagnóstico para a criança desacompanhada de uma autorreflexão da escola sobre o seu trabalho com a criança pode ser utilizada como justificativa para o não aprendizado.

\section{Resultados e discussão}

A pesquisa bibliográfica realizada no Banco de Teses e Dissertações da Coordenação de Aperfeiçoamento de Pessoal de Nível Superior (CAPES), com temática relacionada ao TDAH, trouxe cinco trabalhos específicos produzidos em programas de pós-graduação em Educação vinculados a universidades brasileiras nos últimos três anos (2017-2019), sendo quatro dissertações de mestrado e uma tese de doutorado, o que revela que a temática do TDAH tem sido poucas vezes objeto de investigação científica na área de Educação. Destes trabalhos, três focam em habilidades de leitura e escrita de crianças com diagnóstico de TDAH (ENRICONE, 2017; PEREIRA, 2017; SOUZA, 2017).

Embora tenhamos optado pela discussão dos trabalhos encontrados no Banco de Teses e Dissertações da CAPES, pela sua abrangência nacional, procuramos ainda investigar os trabalhos de pesquisa dos Programas de Pós-Graduação em Educação do Centro de Educação da Universidade Federal de Alagoas (PPGE/CEDU/UFAL) e do Programa de Pós-graduação em Educação da Faculdade de Filosofia e Ciências da Universidade Estadual Paulista "Júlio de Mesquita Filho" (PPG/FFC/UNESP), de modo a realizarmos um cotejo com os trabalhos localizados no Portal CAPES. A opção pelos dois programas de pós-graduação destas duas universidades, uma estadual e outra federal, se justifica por se tratar das instituições de vínculo dos autores do artigo e pelos limites do texto.

No caso do Programa de Pós-Graduação em Educação da Faculdade de Filosofia e Ciências da UNESP foram encontrados quatorze trabalhos sobre TDAH nos últimos três anos (2017-2019), sendo oito dissertações de mestrado e seis teses de doutorado. No Programa de Pós-Graduação em Educação do Centro de Educação da UFAL não foi localizada nenhuma pesquisa sobre TDAH no período de 2017 a 2019. O número maior de trabalhos sobre TDAH 
no Programa de Pós-graduação da UNESP de Marília (Faculdade de Filosofia e Ciências FFC), quando comparado com o banco de teses e dissertações da CAPES e com o PPGE/CEDU/UFAL, pode estar relacionado com a tradição de pesquisas da FFC no campo da educação inclusiva, com aprofundamentos na área para o curso de Pedagogia e uma linha de pesquisa específica no Programa de Pós-Graduação. Dados os limites deste artigo, discutiremos aqui, de modo mais específico, os trabalhos localizados na Banco de Teses e Dissertações da CAPES.

Enricone (2017) afirma que os TDAH, como o baixo desempenho na leitura, estão vinculados a déficits em determinados domínios neurocognitivos. Após avaliar 73 estudantes com TDAH, do $3^{\circ}$ ao $9^{\circ}$ ano do Ensino Fundamental, a autora destaca que os parâmetros de fluência e precisão tiveram crescimento com a escolaridade e a idade, o que não ocorreu na compreensão leitora. A autora considera que seus resultados de pesquisa são relevantes pois afirmam haver uma co-ocorrência de TDAH e dificuldades de leitura e indica a necessidade de utilizar esses resultados para subsidiar intervenções pedagógicas adequadas para estes estudantes.

Pereira (2017) analisou uma amostra de erros ortográficos em dois estudos, um com crianças do $3^{\circ}$ ao $5^{\circ}$ ano do Ensino Fundamental, com e sem diagnóstico de TDAH, e o outro comparando os erros ortográficos de estudantes com diagnóstico de TDAH do $5^{\circ}$ e $6^{\circ}$ ano com estudantes do $7^{\circ}$ e $8^{\circ}$ ano. A autora classificou os tipos de erros ortográficos cometidos e, com uso de um modelo estatístico, concluiu que os tipos de erros ortográficos que envolvem memorização incorrem em maior prejuízo para estudantes com TDAH. Para a autora, com o aumento da escolaridade, esses erros deveriam estar sendo superados e sugere reflexões a respeito de "[...] possibilidades de intervenção, tanto clínica quanto escolar, que promovam a aprendizagem desse grupo de estudantes, pois, a escola recebe alunos com ritmos distintos e que necessitam de propostas de ensino diferenciadas" (PEREIRA, 2017, p. 77).

Souza (2017) realizou pesquisa sobre TDAH a partir de perspectivas da Psicologia Histórico-Cultural, em especial Leontiev, para discutir a "atividade do estudo" e ressalta que a criança precisa ser inserida em atividade pelo adulto (SOUZA, 2017, p. 116). A autora considera "que não existe uma disfunção neurológica no indivíduo com TDAH, mas sim uma atividade de estudo que não vem ocorrendo de maneira efetiva" (p. 118) e chama a atenção para a importância do trabalho do professor como mediador entre o conhecimento e a criança.

Scarabucci (2017) investigou como a escola procede para viabilizar o ensino e a aprendizagem da criança diagnosticada com TDAH. A autora pesquisa as ações pedagógicas planejadas para a criança com TDAH, suas interações no espaço escolar e reflete de que 
maneira a Psicopedagogia pode respaldar a prática docente com essas crianças. Nas escolas onde o estudo foi desenvolvido, os/as profissionais (docentes, gestores etc.) desconhecem e ignoram as características do TDAH, considerando a criança diagnosticada como essencialmente hiperativa e têm ações muito mais voltadas para os aspectos comportamentais do que para as questões pedagógicas. A totalidade de entrevistados (profissionais, familiares e crianças) afirma que o uso de medicação é positivo, mas requer a ação pedagógica correspondente para auxiliar às necessidades específicas da criança.

A predominância de trabalhos encontrados sobre a relação entre TDAH e leitura e escrita nos aponta para uma dupla secundarização das outras áreas do conhecimento, quando o assunto está vinculado às crianças com dificuldades escolares: em primeiro lugar, outras áreas ficam em segundo plano, tendo em vista haver maior valorização da área de língua portuguesa em detrimento de outras e, em segundo lugar, no caso das crianças com dificuldades, lhes são negligenciados os direitos às experiências com outras áreas na medida em que se considera o domínio do código escrito como única via de acesso à informação, ao conhecimento e a experiências outras.

O artigo 41 das DCNEF (BRASIL, 2010) afirma que os projetos pedagógicos e os regimentos das instituições devem contemplar a melhoria das condições de acesso e de permanência dos estudantes com deficiência, com transtornos globais do desenvolvimento e com altas habilidades nas classes comuns, intensificando a inclusão nas instituições públicas e privadas, de modo a buscar a universalização do atendimento. Embora o artigo 41 não cite as crianças com TDAH como alvo da educação especial na perspectiva da educação inclusiva, o fato de mencionar a intensificação da inclusão e a universalização do atendimento nos permite considerar que as crianças com TDAH devem estar contempladas.

Segundo Araújo, Cordeiro e Giroto (2019, p. 777), esse objetivo expresso nas diretrizes curriculares só farão sentido se as crianças forem consideradas como atores sociais que "[...] interagem e desenvolvem num espaço e tempo compartilhados com outras pessoas", portanto, é importante dar voz às crianças nas práticas pedagógicas. Nessa mesma direção, Giroto, Vitta e Araújo (2019) afirmam que o trabalho educativo num contexto da Educação Inclusiva, partindo dos princípios da universalização, da igualdade de direitos, reafirmam a necessidade de que sejam consideradas as especificidades das crianças, os diferentes contextos e suas diversas formas de apropriação do conhecimento e da valorização das diferenças.

Apresentamos a seguir o relato da mãe de Ítalo e, na sequência, algumas reflexões, considerando o diagnóstico, a relação família-escola e as possíveis implicações para a 
organização da estrutura e do funcionamento da escola e para a formação docente.

As queixas da escola em relação ao comportamento de Ítalo começaram quando ele tinha 6 anos de idade. Na ocasião, ele estudava em outra escola privada da mesma cidade. As queixas da instituição diziam respeito ao comportamento dele e não a sua aprendizagem. Queixavam-se de que o Ítalo agia por impulso, que era hiperativo, que muitas vezes ficava agitado, mexendo em seus materiais, inquieto e muitas vezes apresentava comportamento opositor, principalmente quando era questionado $e$ confrontado com as regras da escola. Após muita insistência da escola desde 2018 para que nós procurássemos ajuda de um profissional da área da saúde, em 2019 levamos o Ítalo a um neurologista infantil. Logo na primeira consulta o psiquiatra indicou o uso de Metilfenidato (Ritalina LA). A primeira semana de medicação foi muito complicada. O Ítalo ficou inquieto, agitado, não conseguia parar sentado para realizar as tarefas de escola. Entramos em contato com o médico que, imediatamente, suspendeu o medicamento e prescreveu a Imipramina e Risperidona para auxiliar o Ítalo no que diz respeito a um possivel transtorno de ansiedade. O Ítalo realmente é muito ansioso no seu dia-a-dia, principalmente para lidar com questões de espera. Ele mastiga a gola de sua camiseta constantemente. Passamos, também a procurar por sessões de psicoterapia. A busca por terapeutas também foi difícil. O Ítalo foi atendido por três psicoterapeutas até encontrar uma profissional que atuasse com a terapia comportamentalista. Na mesma época em que o trabalho com a terapia foi iniciado, a escola me telefonava insistentemente afirmando que o Ítalo havia saído da sala de aula sem pedir, que questionava o posicionamento da professora e incomodava os colegas. O Ítalo tinha um profundo apego a um amigo da mesma turma e, quando não era possível ou permitido que eles ficassem próximos, o Ítalo se irritava profundamente, ficava muito nervoso e se negava a realizar as atividades de sala de aula. Por essa época, eu estava me separando do pai dos meus filhos. Foi um processo muito difícil e doloroso para todo mundo, o que afetou o comportamento das crianças. Elas não entendiam o que estava acontecendo. Minha filha de sete anos iniciou um processo de puberdade precoce e colesterol elevado e o Ítalo, que na época tinha quatro anos, começou a apresentar os problemas relacionados ao comportamento. Toda essa situação foi relatada aos profissionais que acompanhavam a criança (terapeuta e psiquiatra) e também à escola. O processo de separação durou aproximadamente quatro anos, quando ocorreu o divórcio litigioso, também dificil e sofrido. Atualmente, as crianças moram comigo e por diversas situações familiares, estão sob medida protetiva. Como a escola insistentemente solicitava presença e ações da família, fui em busca de um outro médico psiquiatra. A priori, a médica manteve a medicação que o Ítalo estava tomando para futuramente, iniciar a retirada com redução da dose da medicação Risperidona, que segundo ela era muito forte para ele. $O$ Ítalo permanece sendo acompanhado por esta médica psiquiatra até o momento. Em meio a esse processo, dada a relação estremecida entre escola-família, mudamos o Ítalo de escola. Logo que escolhemos a escola e fizemos a matrícula, relatamos às gestoras toda a situação do Ítalo e o contexto no qual ele estava inserido. A escola manifestou-se preparada para lidar com tal situação. No entanto, essa mudança foi muito difícil. O Ítalo não queria sair da escola anterior. Ele se mostrou opositor em relação a tudo que dizia respeito ao novo colégio. Depois, com o trabalho de aproximação realizado pela escola atual, ele fez alguns amigos e passou a ter como referência alguns profissionais da escola. No entanto, nesse

RIAEE - Revista Ibero-Americana de Estudos em Educação, Araraquara, v. 15, n. esp. 5, p. 2899-2915, dez. 2020. e-ISSN: 1982-5587 DOI: https://doi.org/10.21723/riaee.v15iesp5.14565 
periodo ele recebeu inúmeras advertências e uma suspensão por três dias que, segundo a escola, tem caráter educativo. Logo começaram as queixas da escola em relação ao comportamento do Italo, afirmando seu mal comportamento. Nos telefonemas, reclamavam de dificuldades dele em obedecer às regras e que às vezes ele saía da sala de aula sem pedir autorização. Eu era chamada constantemente para que a escola me notificasse dos ocorridos. Em nenhuma das reuniões foram apresentados quaisquer avanços do Ítalo em relação ao comportamento, discurso muito diferente do que é falado pelos profissionais que o acompanham. Nessas conversas, o discurso da escola é sempre negativo em relação ao meu filho e solicitam ajuda médica, dos pais e a busca por um laudo definitivo. Em uma das vezes em que minha presença à escola foi solicitada porque não sabiam que medidas tomar, havia quatro profissionais em cima do Ítalo, aguardando até que eu chegasse à escola. Assim que me viram, começaram a relatar o ocorrido: o Ítalo havia se negado a assistir uma peça teatral e havia fugido. Ao mesmo tempo ficavam reiterando na frente dele vários aspectos negativos do seu comportamento, sobretudo em relação ao regulamento da escola. Tenho questionado a escola sobre os encaminhamentos metodológicos que poderão ser tomados após uma conclusão diagnóstica, mas a escola é firme em apoiar-se apenas no regimento da instituição e que não abrirá mão do cumprimento de tal regulamento. Além disso, até agora não me foi dada a possibilidade de conversar com a professora da turma do meu filho sobre a situação dele. Em uma das conversas com a escola, a orientadora educacional afirmou que em duas ocasiões o Ítalo havia agredido a coordenadora da escola. Em casa e em outros espaços sociais, o Ítalo tem mostrado amadurecimento e progresso em relação ao comportamento e ele nunca se mostrou uma criança de comportamentos violentos. O Ítalo me diz que não se sente querido pelos colegas. São poucas as crianças que se aproximam e ele próprio relata que tudo o que acontece em sala de aula é de responsabilidade dele. Ainda assim, ele manifesta carinho pelos amigos e não deseja a mudança de escola. O Ítalo não tem problemas de aprendizagem, mas mesmo assim ele foi encaminhado para atividades de apoio. Ele tem tirado boas notas e tem muito interesse e gosto pela área de exatas. Dialoga e argumenta muito bem, fazendo uso de vocabulário rico e diversificado. Gosta de pesquisar e buscar fundamento para o que está sendo dito. Adora ler gibis e temáticas de seu interesse. Gosta de assistir filmes e passar horas brincando com jogos de montar. Após dois anos de investigação e acompanhamento, a hipótese diagnóstica enviada pela psiquiatra é de TDAH em comorbidade com transtorno depressivo-ansioso na infância. Hoje o Ítalo está medicado e faz acompanhamento psiquiátrico e psicológico semanalmente. $O$ relatório médico onde consta a hipótese diagnóstica do Ítalo foi enviado para a escola, que continua insistindo para que o profissional vá até lá para conversar.

Ao analisarmos o excerto, a partir dos dois eixos: o diagnóstico e a relação famíliaescola, há de se reconhecer as implicações desse processo de busca por um possível diagnóstico e do modo de construção das relações entre a família e a escola na vida da criança. Além disso, há de se refletir acerca de algumas implicações: O que acontece quando a criança não corresponde às expectativas da escola? Que possíveis caminhos vão sendo trilhados no processo de avaliação diagnóstica? Como se constrói a relação família-escola a 
partir do momento em que há hipótese diagnóstica de TDAH de modo a contribuir para a superação das possíveis dificuldades da criança? Estes são questionamentos que orientam nossas reflexões a seguir.

\section{E quando a criança não corresponde ao que a escola espera? A criança em processo de avaliação diagnóstica}

Apresentamos algumas reflexões a respeito da avaliação diagnóstica a que são submetidas as crianças que não correspondem àquilo que a escola espera delas. Não se trata de criticar a necessidade de encaminhamento de determinados casos para serem avaliados com a colaboração de profissionais de outras áreas, mas de refletir a respeito dos modos pelos quais estas decisões de encaminhamento são tomadas e em que medida a escola e a família estabelecem diálogo e parceria pensando na formação integral e no bem estar da criança. Trata-se ainda de pensar sobre os objetivos de uma avaliação diagnóstica com profissionais da saúde: ajudar a criança a trilhar seus percursos de aprendizagens ou responsabilizá-la por aquilo que ela ainda não consegue fazer sem auxílio?

Freitas e Baptista (2019, p. 795) mencionam a necessidade de cautela com excessos no diagnóstico e as implicações que o acompanham, na medida em que podem levar à exclusão, à estigmatização e à rotulação da pessoa, evidenciando “[...] sua história e sua trajetória necessariamente vinculada a redes de pertencimento" do transtorno.

Moysés e Collares (2011) e Signor (2013) também questionam fragilidades dos critérios utilizados para diagnosticar as crianças e medicalizá-las. Afirmam que algumas crianças, por serem mais ativas do que aquilo que os adultos consideram como padrão, ou por apresentarem ritmos de aprendizagens diferentes, passam a vivenciar a estigmatização da escola e tudo que vem decorrente dela, como a questão da constituição da subjetividade, da aprendizagem e da socialização da criança.

Em caso de necessidade, o uso de medicação pode ser usado, desde que receitado e acompanhado por profissionais da saúde, sendo aliado a tratamentos psicoterapêuticos, como formas de auxiliar no cotidiano da criança com TDAH. No entanto, defendemos que isso deve ser avaliado por uma equipe multidisciplinar de profissionais de modo a evitar qualquer uso indiscriminado e desnecessário de medicamentos. É necessário discutir, também, o papel da escola na realização de um trabalho pedagógico que contemple a diversidade de indivíduos a quem educa e na promoção de atividades específicas que contribuam para a superação das dificuldades escolares das crianças a partir de seus interesses e de suas necessidades. 


\section{Relação família-escola: e quando se tem a hipótese diagnóstica da área da saúde?}

O relato anunciado revela o modo pelo qual a instituição escolar em que Ítalo estuda parece utilizar o discurso da obediência às regras e normas para culpabilizá-lo pela não adaptação ao cotidiano e às formas de interação social exigidas naquele ambiente institucional. A observação do "regimento" é sempre utilizada como argumento.

A equipe pedagógica parece assumir uma postura defensiva em relação à criança nas conversas com a sua família. A mãe de Ítalo relata que a situação de conversa com a equipe escolar é sempre unilateral, ressaltando como negativo o comportamento da criança e sua dificuldade em se ajustar ao regimento da escola. Ademais, a mãe destaca que nas reuniões solicitadas pela escola foi ressaltada a necessidade do respeito ao regimento da escola pela criança. $\mathrm{O}$ discurso da equipe pedagógica sempre se fundamentou no uso de tal regimento e na necessidade em se estabelecer e seguir um padrão de comportamento. Em outras palavras, a escola espera que as crianças cumpram o "ofício de aluno" (PERRENOUD, 1995), que é amplamente conhecido, mas nem sempre orientado objetivamente pelas instituições. A escola de Ítalo não informa quais procedimentos metodológicos, por exemplo, estariam sendo planejados após o recebimento da hipótese diagnóstica definitiva da criança.

O relato aponta para tentativa familiar de encontrar uma solução para aquilo que a escola considera como um problema e, embora a mãe indique avanços da criança a partir daquilo que é descrito pelos médicos e terapeutas que a acompanham, a gestão da escola continua ressaltando o comportamento de Ítalo como negativo, cobrando ações de ajuda da família e que esta busque apoio de profissionais da saúde. Como mencionado anteriormente, não nos cabe questionar a necessidade do acompanhamento de outros possíveis profissionais, mas discutir que a escola também precisa olhar para o trabalho que está desenvolvendo e se questionar a respeito do modo pelo qual vem lidando com a diversidade e a diferença.

Para Foucault (2002), a norma tem como principal função o controle e a disciplina do corpo e de uma sociedade, trazendo o discurso que definirá aquilo que deve ser considerado como padrão. As normas imprimem o modo de se comportar e de viver. Moysés e Collares (2010, p. 54) ressaltam que a medicalização também se constitui num processo de normalização, justificado por comportamentos que retratam modos diferentes de ideal de normalidade, isentando da responsabilidade os possíveis contextos e agentes geradores dos tais problemas. Sendo assim, a lógica medicalizante muitas vezes é fortalecida no discurso dos professores, culpabilizando a criança e as famílias pelas dificuldades escolares.

Diante da criança com quem não consegue lidar, por ser considerada mais atuante e 
comunicativa, a escola nega a possibilidade de refletir sobre sua organização interna e suas regras e se isenta da busca por um trabalho pedagógico que procure ensinar a todos. Essas crianças desestabilizam seus professores por direcionarem o olhar desses adultos a partir do movimento de seus corpos. Quando tal situação acontece, o diagnóstico frequentemente nomeia esse estudante como hiperativo. Esta sigla - TDAH - funciona, como diria Foucault, como um dobramento do sujeito, na medida em que ao projetar o discurso sobre a criança, o adulto a transforma no próprio diagnóstico, passando a ser este seu próprio nome (FREITAS; BAPTISTA, 2019). Além disso, é preciso considerar o movimento com uma necessidade da criança e, nesse sentido, a escola também precisa refletir a respeito dos tempos e dos espaços que têm sido destinados para as necessidades de movimento das crianças.

Esse argumento fundado na observância do "regimento escolar" mostra um dos mecanismos pelos quais a escola abdica do trabalho com a diversidade e a diferença. Ao propor o trabalho educativo baseado na obediência e subserviência ao regulamento, a escola está preparando seres humanos para aceitar quaisquer condições que o mundo social lhes impuser. Mais grave ainda é o fato de que a escola, ao se proteger atrás do escudo do regimento, ignora sistematicamente o trabalho pedagógico com a diversidade e a diferença.

A repulsa à diversidade e à diferença evidencia o pressuposto de que certos agentes educacionais entendem que a escola não é um ambiente adequado para quem tiver dificuldades em se adaptar a ele. Evidencia, também, o pressuposto de que ser diferente é um problema que não merece acolhimento.

A relação da escola com a família de Ítalo parece ser construída a partir de tentativas reiteradas de impor forças de poder, sendo a instituição a detentora do saber que deve ser transmitido às crianças e à família caberia controlar o menino. As reiteradas falas das funcionárias da gestão escolar para que a mãe de Ítalo ajudasse a escola revela as possíveis implicações do diagnóstico para os envolvidos e para a formação docente.

No que se refere ao diagnóstico da criança com TDAH, esse é um processo moroso e que exige uma equipe multidisciplinar que precisa considerar a trajetória e o contexto da criança na vida e na escola, exatamente para evitar que seja estigmatizada por um possível transtorno. Por ser um processo longo, demorado e contínuo, é importante que a família e a escola trabalhem numa relação de parceria e complementaridade.

Temos aqui um caso que exemplifica diversos possíveis excessos cometidos em relação às crianças, que são submetidas a uma série de inúmeros e exaustivos exames para investigar a hipótese do TDAH. Nesse processo, o sujeito deixa de ser visto pela escola como uma pessoa e passa a ser visto como "um TDAH". "Se alguém introduz o diagnóstico 
precocemente, e trata-a como se fosse 'um TDAH', no final pode ter razão" (UNTOIGLICH, 2006, p. 16), uma vez que toda a visão e percepção das esferas sociais onde o indivíduo se relaciona passam a vê-lo como portador de "um TDAH". As queixas mais frequentes da escola a respeito de Ítalo voltam-se para problemas relacionados ao comportamento, sobretudo à dificuldade de lidar com as regras impostas pela escola e não com as questões relacionadas à aprendizagem.

O depoimento indica que a família não percebe Ítalo como uma criança agressiva nem em casa e nem em outros espaços sociais nos quais ele circula e convive. No entanto, Ítalo constantemente recebe sanções por problemas relacionados ao comportamento e uma alegada agressividade. Chama a atenção o fato de que quando a família é chamada pela coordenação na escola, a professora não é chamada para a conversa com a mãe, somente a orientadora educacional e a coordenadora da instituição.

A reflexão que propomos para esse caso é a de uma interpretação "de dentro", uma experiência centrada nas situações, histórias, condutas e nos discursos (CHARLOT, 2000, p. 18). Para o autor, esta perspectiva leva à compreensão do estudante como um sujeito, ou seja, um ser "humano", "social" e "singular" que "age no e sobre o mundo"; como ser social estabelece contatos com vários âmbitos de (con)vivência, encontrando "a questão do saber como necessidade de aprender"; e como ser singular "se produz ele mesmo e é produzido" através de situações de educação (CHARLOT, 2000, p. 33).

Diante de tantos desafios e entraves, que caminhos as instituições educacionais podem ter pela frente para trabalhar, junto com as famílias, a educação das crianças com dificuldades escolares? Entendemos que não há receituário. As ações que podem ser bem sucedidas em um contexto não necessariamente podem ser aplicadas igualmente em outras situações e pessoas. Ainda assim, como é na instituição escolar que atuam os docentes das infâncias, acreditamos que a escola pode ser uma referência de fundamental apoio à criança e à família, especialmente no que se refere à uma educação que emancipe as crianças e que considere e respeite a diversidade e a diferença.

\section{Considerações finais}

Este artigo teve como objetivo analisar o modo pelo qual uma instituição educacional tem respondido a casos de crianças com hipótese diagnóstica de TDAH, do ponto de vista do trabalho pedagógico e da relação com a família. Optamos por discutir parte da história de Ítalo a partir da narrativa tecida por sua mãe como responsável que vivenciou o processo de 
busca por um diagnóstico a partir da solicitação da escola. Foi possível verificar que, embora a narrativa da mãe aponte para o acompanhamento da vida escolar do filho, seguindo as orientações e solicitações da escola em relação à investigação de um possível transtorno de déficit de atenção e/ou hiperatividade, mesmo com a hipótese diagnóstica em mãos, a escola continuou responsabilizando a família pela dificuldade da criança, sem olhar para sua responsabilidade nessa relação de complementaridade entre família e escola.

Também foi possível perceber que a queixa escolar não se concentrava em dificuldades de aprendizagem, mas era de ordem comportamental, o que nos levou a discutir que as dificuldades escolares nem sempre estão diretamente relacionadas única e exclusivamente à aprendizagem e que o ofício de aluno exigido pela instituição escolar vai além dos aspectos cognitivos e da aprendizagem de conteúdos vinculados às diversas áreas do conhecimento, mas também envolve uma expectativa dos adultos a respeito de um "modo de ser da escola" que estes entendem que deve ser seguido pelas crianças e adolescentes, muitas vezes sem questionamento e participação ativa.

Mediante pesquisa bibliográfica e estudo de caso, optamos por trazer um recorte do caso de Ítalo a partir da narrativa de sua mãe. O levantamento bibliográfico realizado evidencia que parcela significativa dos trabalhos sobre TDAH parecem focar na descrição das dificuldades consideradas típicas de crianças e adolescentes diagnosticados com o transtorno, especialmente aquelas voltadas para a aprendizagem da leitura e da escrita e a construção de estratégias com profissionais de apoio. No entanto, faltam pesquisas sobre o trabalho pedagógico das escolas para contribuir com a superação das dificuldades, investigações sobre as relações entre as escolas e as famílias e estudos sobre e na perspectiva das próprias crianças sobre suas dificuldades na escola.

Compreendemos que dar voz à criança e sua família pode ajudar a equilibrar a balança nas relações de poder mesmo no campo acadêmico sobre o TDAH, ao trazer à luz as falas e percepções das famílias sobre suas crianças e sobre a escola.

A fala da mãe de Ítalo nos possibilitou dois eixos de análise e interpretação: o diagnóstico e a relação família-escola. A mera indicação de que a família procure ajuda profissional para investigação de um possível transtorno está envolvido em conflitos e traz muitas angústias para a família. Procuramos chamar a atenção para as dificuldades na definição de um diagnóstico de TDAH, já que exige inúmeros exames e consultas com equipe multiprofissional.

Discutimos que a relação escola-família pode se tornar uma relação tensa se a instituição não estiver aberta às formas de diversidade que os/as estudantes apresentam. As 
famílias podem se sentir desprotegidas, dada a fragilidade que a hipótese de ter um filho com um transtorno pode acarretar e sem forças nos jogos de poder em relação à escola. Vimos no artigo que a escola na qual Ítalo estudava assumia a defesa do regimento escolar como uma estratégia de defesa e desresponsabilização do trabalho pedagógico com a diversidade e a diferença e utilizava sua posição favorável nas relações de poder para culpabilizar a família por não contribuir com a instituição.

Por fim, destacamos a importância do papel da escola como uma instituição que deve ser parceira da família - e vice-versa - em todo o processo de educação das crianças, e procuramos chamar a atenção para a necessidade de que a escola acolha a diversidade e a diferença, evitando excessos em relação às crianças, afastando possíveis visões das crianças como se fossem "um TDAH”, mas sobretudo procurando destacar em cada criança singular suas características, que as fazem únicas. Este nos parece o princípio da ideia de uma escola inclusiva: planejar pensando naquele/a que tem dificuldades para que todos possam usufruir de uma educação emancipatória e equitativa.

\section{REFERÊNCIAS}

ANJOS, C. I.; SILVA, S.; SILVA, C. N. O. Políticas, formação docente e práticas pedagógicas: reflexões acerca de uma Educação Infantil inclusiva. Revista Ibero-Americana de Estudos em Educação, Araraquara, v. 14, n. esp. 1, p. 641-655, abr. 2019. DOI: https://doi.org/10.21723/riaee.v14iesp.1.12196

ANDRÉ, M. E. D. A. Estudo de caso em pesquisa e avaliação educacional. Brasília: Líber Livro Editora, 2005.

ARAUJO, L. A.; CORDEIRO, A. P.; GIROTO, C. R. M. Um encontro com a diversidade na Educação Infantil por meio do projeto "Simplesmente Diferente" sob a perspectiva do professor, da criança e da família. Revista Ibero-Americana de Estudos em Educação, Araraquara, v. 14, n. esp. 1, p. 775-790, abr. 2019. E-ISSN: 1982-5587. DOI:

https://doi.org/10.21723/riaee.v14iesp.1.12206

BRASIL. Ministério da Educação. CNE/CEB. Diretrizes Curriculares Nacionais para o Ensino Fundamental. Brasília, 2010.

CHARLOT, B. Da relação com o saber: elementos para uma teoria. Porto Alegre: Artes Médicas, 2000. 93 p.

CLANDININ, J.; CONNELY, M. Narrative inquiry: experience and story in qualitative research. San Fracisco: Jossey-Bass, 2000. In: CRESWELL, J. W. Projeto de pesquisa: métodos qualitativo, quantitativo e misto. 3. ed. Porto Alegre: Artmed, 2010.

CORREA, K. B.; CABRAL, S. B. Transtorno do Déficit de Atenção e Hiperatividade - 
TDAH. ASSOCIAÇÃO BRASILEIRA DO DÉFICIT DE ATENÇÃO - ABDA. Disponível em: www.tdah.org.br. Acesso em: 1 mar. 2020.

ENRICONE, J. R. B. Caracterização da Leitura e Funções Neuropsicológicas de

Estudantes com TDAH. 2017. 164 f. Tese (Doutorado em Educação) - Universidade Federal do Rio Grande do Sul, Porto Alegre, 2017. Disponível: http://hdl.handle.net/10183/198754. Acesso em: 31 mar. 2020.

FOUCAULT, M. Os anormais. Curso no Collège de France (1974-1975). São Paulo: Martins Fontes, 2002.

FREITAS, C. R.; BAPTISTA, C. R. Mais rápidas que a escola: crianças referidas como hiperativas no contexto escolar. Revista Ibero-Americana de Estudos em Educação, Araraquara, v. 14, n. esp. 1, p. 791-806, abr. 2019. DOI:

https://doi.org/10.21723/riaee.v14iesp.1.12207

GIROTTO, C. R. M.; ARAUJO, L. A.; VITTA, F. C. F. Discursivização sobre “doenças do não aprender" no contexto educacional inclusivo: o que dizem os professores de Educação Infantil? Revista Ibero-Americana de Estudos em Educação, Araraquara, v. 14, n. esp. 1, p. 807-825, abr. 2019. DOI: https://doi.org/10.21723/riaee.v14iesp.1.12208

GIROTTO, C. R. M.; VITTA, F. C. F.; ARAUJO, L. A. Dossiê Inclusão e Educação Infantil. Revista Ibero-Americana de Estudos em Educação, Araraquara, v. 14, n. esp. 1, p. 635640, abr. 2019. DOI: https://doi.org/ https://doi.org/10.21723/riaee.v14iesp.1

MOYSÉS, M. A. A.; COLLARES, C. A. L. A transformação do espaço pedagógico em espaço clínico (a patologização da educação). Campinas: FAPESP/Mercado de Letras, 1994.

MOYSÉS, M. A. A.; COLLARES, C. A. L. Dislexia e TDAH: uma análise a partir da ciência médica. In: Medicalização de crianças e adolescentes: conflitos silenciados pela redução de questões sociais a doença de indivíduos. Conselho Regional de Psicologia de São Paulo. São Paulo: Casa do Psicólogo, 2010. p. 125-156.

MOYSÉS, M. A. A.; COLLARES, C. A. L. Medicalização: o obscurantismo reinventado. In: COLLARES, C. A. L.; MOYSÉS, M. A. A.; RIBEIRO, M. C. F. (Org.). Novas capturas, antigos diagnósticos na era dos transtornos. São Paulo: Mercado de Letras, 2013. p. 41- 64.

PEREIRA, C. S. Desempenho ortográfico de estudantes com TDAH: um estudo sobre a tipologia de erros da Língua Portuguesa. 2017. 80 f. Dissertação (Mestrado em Educação) Universidade Federal do Rio Grande do Sul, Porto Alegre, 2017. Disponível em: https://sucupira.capes.gov.br/sucupira/public/consultas/coleta/trabalhoConclusao/viewTrabalh oConclusao.jsf?popup=true\&id_trabalho=5040968. Acesso em: 15 fev. 2020 .

PEREIRA, F. H. Configurações do ofício de aluno: Meninos e meninas na escola. 2015. 243 f. Tese (Doutorado em Educação) - Universidade de São Paulo, São Paulo, 2015.

PERRENOUD, P. Ofício de aluno e sentido do trabalho escolar. Porto (Portugal): Porto Editora, 1995. 
SANCHES, A. C. C. et al. O TDAH e a medicalização da aprendizagem: enfrentamentos necessários à formação humana. In: TULESKI, S. C.; FRANCO, A. F. (Org.). O lado sombrio da medicalização da infância: possibilidades de enfrentamento. Rio de Janeiro: NAU Editora, 2019. p. 37-67.

SCARABUCCI, C. A. A criança diagnosticada com TDAH: e agora, professor? 2017. 147 f. Dissertação (Mestrado em Educação) - Universidade Federal de Uberlândia, Uberlândia, 2017. Disponível em:

https://repositorio.ufu.br/bitstream/123456789/20324/6/CriancaDiagnosticadaTDAH.pdf. Acesso em: 31 mar. 2020.

SIGNOR, R. C. F. Transtorno de Déficit de Atenção e Hiperatividade: implicações para a constituição leitora do aprendiz. RBLA, Belo Horizonte, v. 16, n. 3, p. 309-334, 2016. DOI: http://dx.doi.org/10.1590/1984-6398201610076

SILVA, K. B. C.; CABRAL, S. B. Transtorno do Deficit de Atenção com Hiperatividade - TDAH. ASSOCIAÇÃO BRASILEIRA DO DEFICIT DE ATENÇÃO - ABDA. Disponível em:

https://tdah.org.br/wpcontent/uploads/site/pdf/cartilha\%20ABDA.final\%2032pg\%20otm.pdf. Acesso em: 2 abr. 2020.

SOUZA, E. P. TDAH (Transtorno de déficit de atenção e hiperatividade): uma análise a partir da atividade de estudo. 2017. 125 f. Dissertação (Mestrado em Educação) - Universidade Estadual Paulista, Presidente Prudente, 2017. Disponível em: http://hdl.handle.net/11449/166177. Acesso em: 15 mar.2020.

UNTOIGLICH, G. Consenso de especialistas da área de saúde sobre o chamado "Transtorno por déficit de atenção com ou sem hiperatividade". Diagnóstico na Infância hoje. APPOA - Associação Psicanalítica de Porto Alegre. POA. Correio APPOA, nº 144, 2006.

\section{Como referenciar este artigo}

ARAÚJO, L. A.; ANJOS, C. I.; PEREIRA, F. H. E quando a criança não corresponde às expectativas da escola? Reflexões sobre a relação com a família na busca por um diagnóstico. Revista Ibero-Americana de Estudos em Educação, Araraquara, v. 15, n. esp. 5, p. 28992915, dez. 2020. e-ISSN: 1982-5587. DOI: https://doi.org/10.21723/riaee.v15iesp5.14565

Submetido em: 10/01/2020

Revisões requeridas em: 25/05/2020

Aprovado em: 30/10/2020

Publicado em: 01/12/2020 